\title{
Role of nitric oxide, tetrahydrobiopterin and peroxynitrite in glucose toxicity-associated contractile dysfunction in ventricular myocytes
}

\author{
L. B. Esberg, J. Ren \\ Division of Pharmaceutical Sciences, University of Wyoming College of Health Sciences, Laramie, USA
}

\begin{abstract}
Aims/hypothesis. Local overproduction of nitric oxide is seen in early stages of diabetes, which can react with superoxide $\left(\mathrm{O}_{2}^{-}\right)$to form peroxynitrite $\left(\mathrm{ONOO}^{-}\right)$. The aim of this study was to examine the effect of scavengers for nitric oxide, $\mathrm{O}_{2}^{-}, \mathrm{ONOO}^{-}$and NOS cofactor tetrahydrobiopterin $\left(\mathrm{BH}_{4}\right)$ on high glucose-induced cardiac contractile dysfunction.

Methods. Ventricular myocytes were cultured for $24 \mathrm{~h}$ with either normal $(\mathrm{N}, 5.5 \mathrm{mmol} / \mathrm{l})$ or high (25.5 mmol/l) glucose, with or without the nitric oxide scavengers haemoglobin $(100 \mathrm{nmol} / \mathrm{l})$, PTIO $(100 \mu \mathrm{mol} / \mathrm{l})$, the NOS inhibitor L-NMMA $(100 \mu \mathrm{mol} / \mathrm{l})$, superoxide dismutase (SOD, $500 \mathrm{U} / \mathrm{ml}$ ), the $\mathrm{ONOO}^{-}$scavengers urate $(100 \mu \mathrm{mol} / \mathrm{l}), \mathrm{MnTABP}$ $(100 \mu \mathrm{mol} / \mathrm{l}), \mathrm{BH}_{4}(10 \mu \mathrm{mol} / \mathrm{l})$ and its inactive analogue $\mathrm{NH}_{4}(10 \mu \mathrm{mol} / \mathrm{l})$, and the GTP cyclohydrolase I inhibitor DAHP ( $1 \mathrm{mmol} / \mathrm{l})$. Myocyte mechanics, NOS protein expression and activity were evaluated.
\end{abstract}

Received: 20 December 2002 / Revised: 27 May 2003

Published online: 29 July 2003

(C) Springer-Verlag 2003

Corresponding author: Dr. J. Ren, Division of Pharmaceutical Sciences, University of Wyoming College of Health Sciences, Laramie, WY 82071-3375, USA

E-mail: jren@uwyo.edu

Abbreviations: PTIO, 2-(4-carboxyphenyl)-4,4,5,5-tetramethyl imidazoline-1-oxyl 3-oxide; DAHP, 2,4-diamino-6-hydroxypyrimidine; E-C, excitation-contraction; MnTABP, manganese (III) tetrakis (4-benzoic acid) porphyrin; $\pm \mathrm{dL} / \mathrm{dt}$, maximal ve-

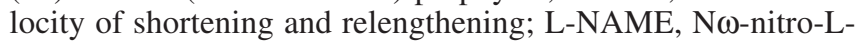
arginine methyl ester; L-NMMA, L-NG-monomethyl-arginine; NOS, nitric oxide synthase; PS, peak shortening; $\mathrm{ONOO}^{-}$, peroxynitrite; $\mathrm{O}_{2}^{-}$, superoxide anion; $\mathrm{SOD}$, superoxide dismutase; $\mathrm{BH}_{4}$, tetrahydrobiopterin; $\mathrm{NH}_{4}$, tetrahydroneopterin; TPS, time-to-peak shortening; $\mathrm{TR}_{90}$, time-to- $90 \%$ relengthening.
Results. High glucose myocytes showed reduced peak shortening, decreased maximal velocity of shortening/relengthening $( \pm \mathrm{dL} / \mathrm{dt})$, prolonged relengthening $\left(\mathrm{TR}_{90}\right)$ and normal shortening duration (TPS) associated with reduced cytosolic $\mathrm{Ca}^{2+}$ rise compared to normal myocytes. The high glucose-induced abnormalities were abrogated or attenuated by urate, MnTBAP, L-NMMA, $\mathrm{BH}_{4}$, and $\mathrm{SOD}$, whereas unaffected by haemoglobin, PTIO and $\mathrm{NH}_{4}$. L-NMMA reduced peak shortening while PTIO and DAHP depressed $\pm \mathrm{dL} / \mathrm{dt}$ and prolonged TPS or $\mathrm{TR}_{90}$ in normal myocytes. High glucose increased NOS activity, protein expression of eNOS but not iNOS, which were attenuated by LNMMA and $\mathrm{BH}_{4}$, respectively.

Conclusion/interpretation. These results suggested that NOS cofactor, $\mathrm{NO}$ and $\mathrm{ONOO}^{-}$play a role in glucose-induced cardiomyocyte contractile dysfunction and in the pathogenesis of diabetic cardiomyopathy. [Diabetologia (2003) 46:1419-1427]

Keywords Glucose, contraction, nitric oxide, NOS, tetrahydrobiopterin, peroxynitrite.
Cardiovascular diseases are among the leading causes of high morbidity and mortality in diabetic populations [1]. Diabetic cardiomyopathy often develops in diabetes and is characterized by systolic and diastolic dysfunctions independent of coronary macrovascular disease [2, 3]. Impaired diastolic function is the most prominent mechanical abnormality manifested as prolonged relaxation and decreased compliance. Several mechanisms have been proposed for the pathogenesis of impaired cardiac excitation-contraction (E-C) coupling, including prolonged action potential duration and altered function of $\mathrm{Ca}^{2+}$-regulating proteins such as $\mathrm{Na} / \mathrm{Ca}$ exchanger and sarco(endo)plasmic reticulum $\mathrm{Ca}^{2+}$-ATPase $[4,5,6]$. However, whether these cellular defects progress as a result of hyperglycae- 
mia or indirectly via glucose toxicity-induced secondary cellular alterations has not been understood completely.

Nitric oxide, an extremely reactive gas with chemical properties of a free radical, is synthesized by a variety of cell types including cardiac, vascular and endothelial cells. It plays an important physiological role in the regulation of cardiac function such as dilation of coronary artery, inhibition of platelet aggregation and biphasic modulation of cardiac contractile function [7, 8]. Nitric oxide also participates in a cascade of pathophysiological processes when formed in excess or in the presence of other pro-oxidants [9]. Enhanced endogenous production of nitric oxide or addition of nitric oxide donors have resulted in compromised cardiac function and enhanced apoptosis $[9,10]$ illustrating the potential toxic properties of nitric oxide. The toxicity of nitric oxide is believed to be associated with its interaction with iron-sulfur-centered enzymes of the respiratory cycle [11]. This is further complicated by superoxide anion $\left(\mathrm{O}_{2}^{-}\right)$, a ubiquitous reaction product of cardiac myocytes during mitochondrial oxidative metabolism. Nitric oxide and $\mathrm{O}_{2}{ }^{-}$react rapidly (second-order rate constant $=6.7 \times 10^{9} \mathrm{M} / \mathrm{s}$ ) to generate peroxynitrite $\left(\mathrm{ONOO}^{-}\right)$, which rapidly decomposes to highly oxidant species such as nitronium ion $\left(\mathrm{NO}_{2}^{+}\right)$[12]. $\mathrm{ONOO}^{-}$can directly initiate lipid peroxidation, protein tyrosine nitration and DNA strand breakdown, as well as interact with iron-sulfur-centered enzymes of the respiratory cycle. It has been implicated that $\mathrm{ONOO}^{-}$can mediate the toxic action of nitric oxide. Paradoxically, nitric oxide also protects against apoptosis and $\mathrm{O}_{2}^{-}$-mediated cell death [13]. Inhibition of nitric oxide synthase (NOS) results in enhanced $\mathrm{O}_{2}^{-}$and $\mathrm{H}_{2} \mathrm{O}_{2}$ production [14], suggesting that a critical balance between nitric oxide and $\mathrm{O}_{2}-$ is required for normal myocyte function.

Altered nitric oxide signalling and enhanced oxidative stress have been suggested to play a role in the pathogenesis of diabetic cardiac complications [15, 16]. Diabetes could alter the activity and expression of NOS $[17,18,19]$. Local overproduction of nitric oxide has been suggested to play an important role in betacell damage and in inducing diabetes. Oxidative stress due to interactions between nitric oxide and oxygenderived radicals has been speculated to represent a common pathological mechanism in increased cardiovascular risk. Recent evidence has suggested that NOS function could be altered in diabetes due to deficiency of tetrahydrobiopterin $\left(\mathrm{BH}_{4}\right)$, a critical cofactor for eNOS [20,21]. Nitric oxide synthase activity is strictly dependent on $\mathrm{BH}_{4}$, the deficiency of which would result in the production of $\mathrm{O}_{2}^{-}$rather than nitric oxide; this phenomenon can be referred to as "eNOS uncoupling" [22]. Peroxymitrite oxidation of $\mathrm{BH}_{4}$ could represent a major pathogenic cause of "eNOS uncoupling" [22]. Both hyperglycaemia and impaired cardiovascular contractile function in diabetes have been shown to be reconciled with the use of NOS inhibitors, superoxide dismutase (SOD) or other antioxidants such as alpha-tocopherol [15], confirming the role of nitric oxide and other reactive oxygen radicals in diabetic heart complications. However, a complete understanding of the mechanisms underscoring the role of nitric oxide in diabetic cardiomyopathy is hampered because few data are available regarding the role of nitric oxide, NOS and nitric oxide-related reactive oxygen species in the onset of diabetic cardiac dysfunctions. We thus took advantage of a cardiac myocyte culture model developed in our laboratory, where the diabetic cardiomyopathy could be phenotypically replicated in normal myocytes by culturing in a high glucose medium $[23,24,25]$. The abnormal cardiac E-C coupling is apparent in high glucose-treated myocytes reminiscent of those from in vivo diabetes [3]. The NOS inhibitor, nitric oxide cofactor and pharmacological scavengers for nitric oxide, $\mathrm{O}_{2}^{-}$and $\mathrm{ONOO}^{-}$were tested to examine the role of nitric oxide, $\mathrm{NOS}^{-}$and $\mathrm{ONOO}^{-}$in the glucose toxicity-induced cardiac mechanical dysfunction simulating diabetic cardiomyopathy.

\section{Methods}

Isolation and culture of isolated ventricular myocytes. The experimental procedure used in this study was approved by the Animal Use and Care Committee at University of North Dakota and University of Wyoming. Briefly, adult male SpragueDawley rats (200-250 g) were anaesthetized with ketamine/xylazine $(5: 3,1.32 \mathrm{mg} / \mathrm{kg}$ i.p.). Hearts were rapidly removed and perfused (at $37^{\circ} \mathrm{C}$ ) with Krebs-Henseleit bicarbonate (KHB) buffer (mmol/1: $\mathrm{NaCl} \mathrm{118,} \mathrm{KCl} 4.7, \mathrm{MgSO}_{4} 1.2, \mathrm{KH}_{2} \mathrm{PO}_{4} 1.2$, $\mathrm{NaHCO}_{3}$ 25, N-[2-hydro-ethyl]-piperazine-N'-[2-ethanesulfonic acid] (HEPES) 10, glucose 11.1, pH 7.4). The heart was then perfused for 20 min with KHB containing $223 \mathrm{U} / \mathrm{ml}$ collagenase (Worthington Biochemical, Freehold, N.J., USA) and $0.5 \mathrm{mg} / \mathrm{ml}$ hyaluronidase (Sigma Chemical, St. Louis, Mo., USA). After perfusion, the left ventricle was removed and minced. The cells were further digested with $0.02 \mathrm{mg} / \mathrm{ml}$ trypsin (Sigma) before being filtered through a nylon mesh $(300 \mu \mathrm{m})$. Extracellular $\mathrm{Ca}^{2+}$ was added incrementally back to $1.25 \mathrm{mmol} / \mathrm{l}$. Isolated myocytes were then cultured in normal $(5.5 \mathrm{mmol} / \mathrm{l})$ or high glucose $(25.5 \mathrm{mmol} / \mathrm{l})$ medium supplemented with or without one of the following drugs; the nitric oxide synthase (NOS) inhibitor $\mathrm{L}_{-\mathrm{NG}}$-monomethyl-arginine (L-NMMA, $100 \mu \mathrm{mol} / \mathrm{l}$ ), the nitric oxide scavenger haemoglobin $(100 \mathrm{nmol} / \mathrm{l})$, the nitric oxide trap 2-(4-carboxyphenyl)4,4,5,5-tetramethyl imidazoline-1-oxyl 3-oxide (carboxyPTIO, $100 \mu \mathrm{mol} / \mathrm{l}$ ) which reacts with nitric oxide to form PTI, superoxide $\left(\mathrm{O}_{2}^{-}\right)$scavenger superoxide dismutase (SOD, $500 \mathrm{U} / \mathrm{ml})$, the NOS cofactor $\mathrm{BH}_{4}(10 \mu \mathrm{mol} / \mathrm{l})$ or peroxynitrite $\left(\mathrm{ONOO}^{-}\right)$scavengers urate $(100 \mu \mathrm{mol} / \mathrm{l})$ and manganese (III) tetrakis (4-benzoic acid) porphyrin (MnTABP, $100 \mu \mathrm{mol} / \mathrm{l}$, which is also a SOD mimetic). To further examine the role of the NOS cofactor $\mathrm{BH}_{4}$, tetrahydroneopterin $\left(\mathrm{NH}_{4}, 10 \mu \mathrm{mol} / \mathrm{l}\right)$, an analogue of $\mathrm{BH}_{4}$, however, without any effect on NOS was co-cultured with the myocytes (obtained from Schircks Laboratories, Jona, Switzerland). In addition, the GTP cyclohydrolase I inhibitor 2,4-diamino-6-hydroxy-pyrimidine (DAHP, $1 \mathrm{mmol} / \mathrm{l}$ ), which inhibits $\mathrm{BH}_{4}$ synthesis, was also incubated with the $\mathrm{N}$ myocytes. Myocytes were maintained for $24 \mathrm{~h}$ before used [23]. 
Cell shortening/relengthening. Mechanical properties of ventricular myocytes were assessed using a video-based edgedetection system (IonOptix, Milton, Mass., USA) [23]. In brief, cells were superfused with a buffer containing (in mmol/l): $131 \mathrm{NaCl}, 4 \mathrm{KCl}, 1 \mathrm{CaCl}_{2}, 1 \mathrm{MgCl}_{2}, 10$ glucose, 10 HEPES, at $\mathrm{pH}$ 7.4. The cells were field stimulated at $0.5 \mathrm{~Hz}$. The myocyte was displayed on the computer monitor using an IonOptix MyoCam camera, which rapidly scans the image area at every $8.3 \mathrm{msec}$ such that the amplitude and velocity of shortening or relengthening is recorded with good fidelity.

Intracellular Ca2+ fluorescence measurement. Myocytes were loaded with fura-2/AM $(0.5 \mu \mathrm{mol} / \mathrm{l})$ for $15 \mathrm{~min}$ and fluorescence measurements were recorded with an IonOptix dualexcitation fluorescence photomultiplier system [23]. Myocytes were imaged through an Olympus $40 \times$ oil objective. Cells were exposed to light emitted by a $75 \mathrm{~W}$ lamp and passed through either a 360 or a $380 \mathrm{~nm}$ filter (bandwidths were $\pm 15 \mathrm{~nm}$ ), while being stimulated to contract at $0.5 \mathrm{~Hz}$. Fluorescence emissions were detected between 480 and $520 \mathrm{~nm}$ after first illuminating cells at $360 \mathrm{~nm}$ for $0.5 \mathrm{~s}$ then at $380 \mathrm{~nm}$ for the duration of the recording protocol ( $333 \mathrm{~Hz}$ sampling rate). The $360 \mathrm{~nm}$ excitation scan was repeated at the end of the protocol and qualitative changes in intracellular $\mathrm{Ca}^{2+}$ concentration $\left(\left[\mathrm{Ca}^{2+}\right]_{\mathrm{i}}\right)$ were inferred from the ratio of the fluorescence intensity at two wavelengths.

Western blot analysis for protein expression of eNOS and $i N O S$. Membrane proteins from normal or high glucose cultured myocytes were extracted as described [26]. Myocytes were collected, sonicated and the supernatants were centrifuged at $7000 \times \mathrm{g}$ for $30 \mathrm{~min}$ at $4^{\circ} \mathrm{C}$. Total cell homogenates from the pellets were used for immunoblotting of eNOS and iNOS. We confirmed that these membrane fractions did not contain any detectable collagens. Membrane proteins (50 $\mu \mathrm{g} /$ lane) were separated on $10 \%$ SDS-polyacrylamide gels in a minigel apparatus (Mini-PROTEAN II, Bio-Rad) and transferred to polyvinylidene difluoride membranes. The membranes were blocked (4\% Block Ace, Dainippon Pharmaceutical; Osaka, Japan) and then incubated for $12 \mathrm{~h}$ with anti-eNOS or anti-iNOS mouse IgG monoclonal antibodies (1:1000, BD Transduction Laboratories, Lexington, Ky., USA). Membranes were then washed and incubated with a horseradish peroxidase-conjugated anti-mouse IgG (1:5000) for $1.5 \mathrm{~h}$. After immunoblotting, the film was scanned and the intensity of immuoblot bands was detected with a Bio-Rad Calibrated Densitometer (Model: GS-800).

NOS activity. Nitric oxide synthase activity was evaluated by the ${ }^{3} \mathrm{H}$-arginine to ${ }^{3} \mathrm{H}$-citrulline conversion assay as described [10]. Briefly, ventricular myocytes were placed in Hanks' Balanced Salt Solution (HBSS) medium containing $1 \mu \mathrm{Ci} / \mathrm{ml}{ }^{3} \mathrm{H}-$ arginine with Trasylol $(0.2 \mathrm{KIU} / \mathrm{ml})$. The cells were incubated for $30 \mathrm{~min}$ before the reaction was terminated by aspiration of the incubation medium and replacement with iced, HBSS containing $5 \mathrm{mmol} / \mathrm{l} \mathrm{L}$-arginine and $4 \mathrm{mmol} / \mathrm{l}$ EDTA. Cells were lysed with $20 \mathrm{mmol} / \mathrm{l}$ TRIS and centrifuged. An aliquot of the supernatant was diluted with 1:1 (v/v) $\mathrm{H}_{2} \mathrm{O} /$ Dowex-50 W (20-50, 8\% cross-linked), and loaded on a polypropylene BioRad EconoColumn. The effluent was collected and ${ }^{3} \mathrm{H}$-citrulline was counted by scintillation.

Statistical analyses. Data are presented as means \pm SEM. Statistical significance was ascertained by ANOVA. Appropriate follow-up tests for multiple comparisons were chosen depending on whether significance $(p<0.05)$ was identified in main effects and/or interaction terms. Data from each drug were anal- ysed separately. Control groups (i.e., $\mathrm{N}$ and high glucose cells) were always recorded on the same day as experimental groups (i.e., with and without drugs) to control for any potential interculture variability.

\section{Results}

Effect of urate, MnTBAP and SOD on high glucose-induced mechanical abnormalities. Culturing myocytes for $24 \mathrm{~h}$ with either high glucose or any drug tested in this study had no overt effect on cell phenotype. Cell shape, resting cell length, and presence of distinct striations were similar in cells among all groups. Representative traces of cell shortening and relengthening are shown in Fig. 1. Consistent with our previous reports [23, 24], myocytes maintained in high-glucose medium had a reduced peak shortening amplitude associated with decreased maximal velocity of shortening and relengthening $( \pm \mathrm{dL} / \mathrm{dt})(p<0.05)$, normal time-to-peak shortening (TPS), and prolonged timeto- $90 \%$ relengthening $\left(\mathrm{TR}_{90}\right)(p<0.05)$ compared to those of normal myocytes. The reduced peak shortening, $\pm \mathrm{dL} / \mathrm{dt}$ and prolonged $\mathrm{TR}_{90}$ in high glucose myo-

A
C
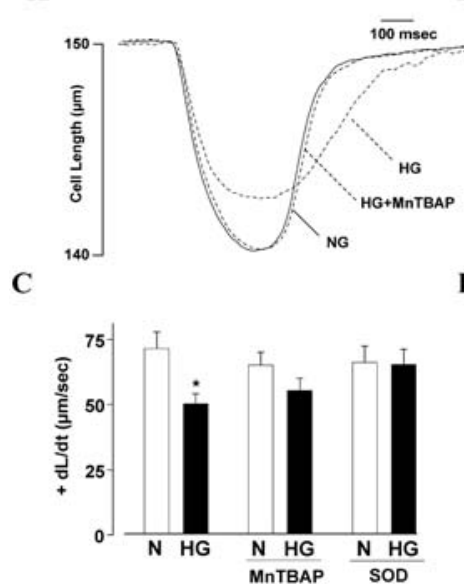

E

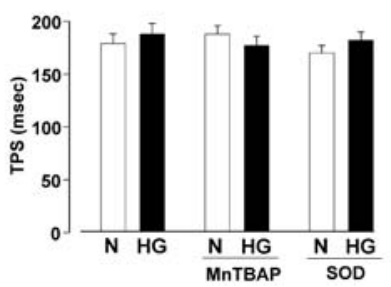

B

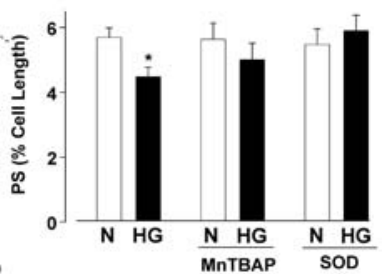

D

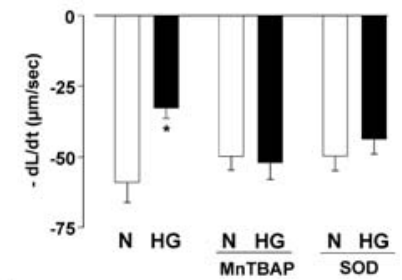

F

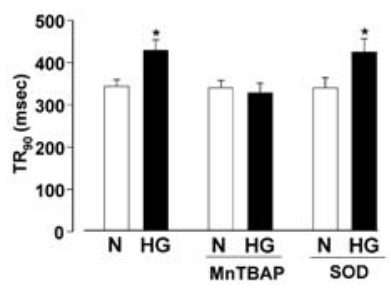

Fig. 1A-F. Representative traces of myocyte cell length from normal glucose (NG: $5.5 \mathrm{mmol} / \mathrm{l}$ ), high glucose (high glucose: $25.5 \mathrm{mmol} / \mathrm{l})$, and high glucose with the $\mathrm{ONOO}^{-}$scavenger MnTBAP $(100 \mu \mathrm{mol} / \mathrm{l})$ groups. B-F Contractile properties of myocytes cultured for $24 \mathrm{~h}$ in normal or high glucose with or without MnTBAP $(100 \mu \mathrm{mol} / \mathrm{l})$ or SOD $(500 \mathrm{U} / \mathrm{ml})$. Mechanical indices are peak shortening (PS), maximal velocities of shortening/relengthening ( $\pm \mathrm{dL} / \mathrm{dt})$, time-to-peak shortening (TPS) and time-to-90\% relengthening $\left(\mathrm{TR}_{90}\right)$. Means \pm SEM, $n=40-57$ cells/group, ${ }^{*} p<0.05$ vs respective normal group 
A

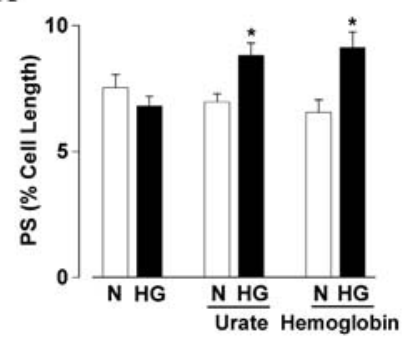

C

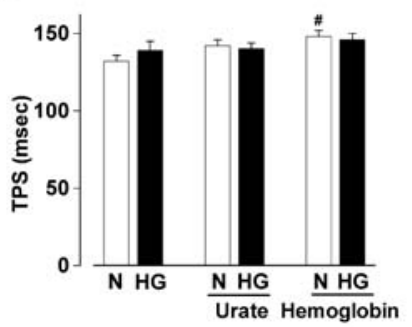

B

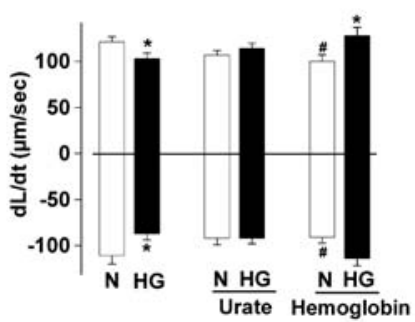

D

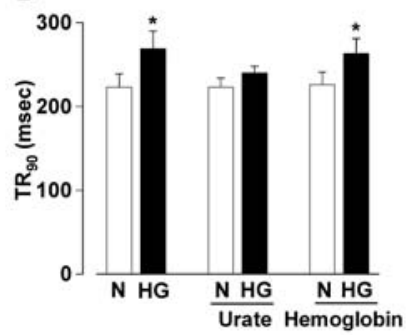

Fig. 2A-D. Contractile properties of myocytes cultured for 18-24 hours in $\mathrm{N}$ or high glucose with or without the $\mathrm{ONOO}^{-}$ scavenger urate $(100 \mu \mathrm{mol} / \mathrm{l})$ or the nitric oxide scavenger haemoglobin $(100 \mathrm{nmol} / \mathrm{l})$. A Peak shortening (PS); B maximal velocities of shortening/relengthening $( \pm \mathrm{dL} / \mathrm{dt}) ; \mathbf{C}$ time-topeak shortening (TPS); D time-to-90\% relengthening $\left(\mathrm{TR}_{90}\right)$; Mean \pm SEM, $n=42-50$ cells/group, $* p<0.05$ vs respective normal group, $\# p<0.05$ vs non-drug supplemented normal group

cytes were abolished by co-incubation the cells with the $\mathrm{ONOO}^{-}$scavengers urate $(100 \mu \mathrm{mol} / \mathrm{l})$ and MnTBAP $(100 \mu \mathrm{mol} / \mathrm{l})$ as well as the $\mathrm{O}_{2}^{-}$scavenger SOD $(500 \mathrm{U} / \mathrm{ml})$, with the exception that SOD did not prevent the high glucose-induced prolonged $\mathrm{TR}_{90}$. In addition, high glucose myocytes maintained with urate showed a significantly increased peak shortening $(p<0.05)$ compared with urate-treated normal myocytes. Urate, MnTBAP or SOD alone had no effect on cell mechanics in normal myocytes (Figs. 1,2).

Effect of L-NMMA, haemoglobin and PTIO on high glucose-induced abnormal mechanical function. Enhanced NOS activity has been shown in myocytes cultured in a high glucose environment [19]. To demonstrate if altered nitric oxide production plays a role in the high glucose-induced mechanical dysfunction, the membrane permeable NOS inhibitor L-NMMA and the nitric oxide scavenger haemoglobin as well as the nitric oxide trap PTIO were examined. L-NMMA (100 $\mu \mathrm{mol} / \mathrm{l})$ unmasked a high glucose-induced potentiation in PS and $\pm \mathrm{dL} / \mathrm{dt}$, whereas it prevented high glucose-induced prolongation in $\mathrm{TR}_{90}$ without affecting TPS (Fig. 3). L-NMMA alone depressed peak shortening in normal myocytes. On the other hand, both PTIO (100 $\mu \mathrm{mol} / \mathrm{l})$ and haemoglobin $(100 \mathrm{nmol} / \mathrm{l})$ nullified the high glucose-induced decrease in peak shortening but depressed $\pm \mathrm{dL} / \mathrm{dt}$ and prolonged TPS in normal myocytes $(p<0.05)$. In addi-

A

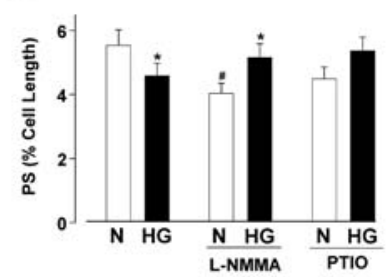

C

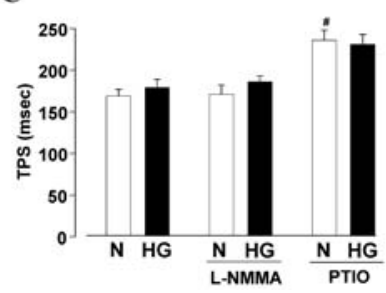

B

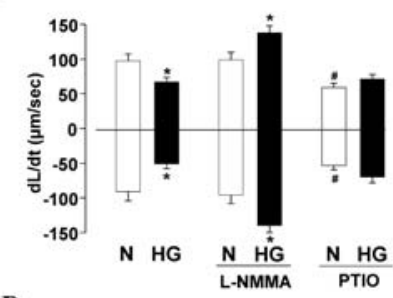

D

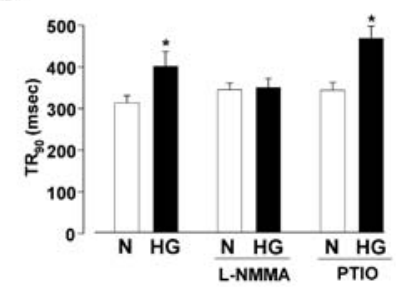

Fig. 3A-D. Graphs illustrate contractile properties of myocytes cultured for $24 \mathrm{~h}$ in normal or high glucose medium with or without the NOS inhibitor L-NMMA $(100 \mu \mathrm{mol} / \mathrm{l})$ or the nitric oxide scavenger PTIO $(100 \mu \mathrm{mol} / \mathrm{l})$. Mechanical indices are peak shortening (PS, panel A), maximal velocities of shortening/relengthening ( $\pm \mathrm{dL} / \mathrm{dt}$, Panel B), time-to-peak shortening (TPS, panel C) and time-to-90\% relengthening $\left(\mathrm{TR}_{90}\right.$, panel $\left.\mathbf{D}\right)$. Means \pm SEM, $n=40-57$ cells/group. ${ }^{*} p<0.05$ vs respective normal group, $\# p<0.05$ vs non-drug supplemented normal group

tion, the high glucose-induced prolongation of $\mathrm{TR}_{90}$ was not affected by either PTIO or haemoglobin (Figs. 2, 3).

Effect of BH4, NH4 and DAHP on myocyte mechanics and NOS protein expression. Diabetes has been shown to lead to reduced concentration of the NOS cofactor $\mathrm{BH}_{4}$ [21]. Our study shows that supplementation of $\mathrm{BH}_{4}(10 \mu \mathrm{mol} / \mathrm{l})$ abrogated the high glucose-induced decline in $\pm \mathrm{dL} / \mathrm{dt}$ and prolongation in $\mathrm{TR}_{90}$, whereas it exerted little effect on mechanical properties in normal myocytes (Fig. 4). However, the $\mathrm{BH}_{4}$ analogue pteridine $\mathrm{NH}_{4}$, an antioxidant but not a NOS cofactor, did not affect the high glucose-induced myocyte mechanical dysfunction at equal molar concentration $(10 \mu \mathrm{mol} / \mathrm{l})$. To further examine the role of $\mathrm{BH}_{4}$ in myocyte mechanics, the GTP cyclohydrolase I inhibitor DAHP $(1 \mathrm{mmol} / \mathrm{l})$, which inhibits $\mathrm{BH}_{4}$ synthesis [20], was co-incubated with normal myocytes for $24 \mathrm{~h}$. Of interest, DAHP depressed $\pm \mathrm{dL} / \mathrm{dt}$, prolonged both TPS and $\mathrm{TR}_{90}(p<0.05)$ without affecting peak shortening in normal myocytes (Fig. 5). In addition, high glucose induced significant increase in protein expression of eNOS $(p<0.05)$, which was nullified by $\mathrm{BH}_{4}$. high glucose did not alter protein expression of iNOS although $\mathrm{BH}_{4}$ itself lowered the iNOS protein expression in high glucose myocytes $(p<0.05)$ (Fig. 4). 
A

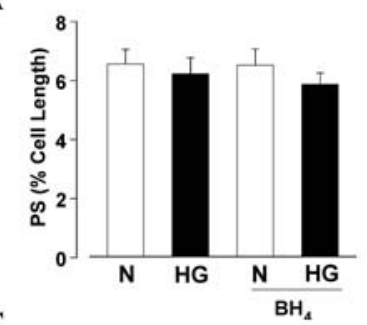

C

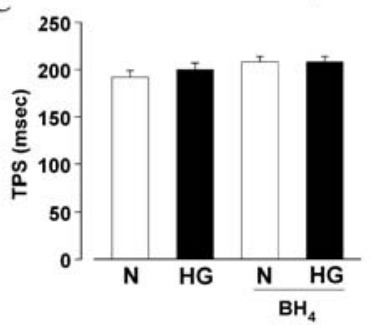

E

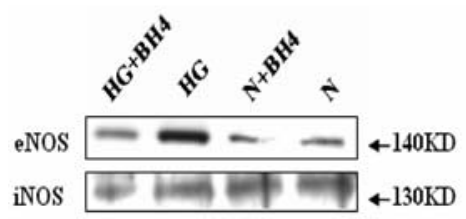

B
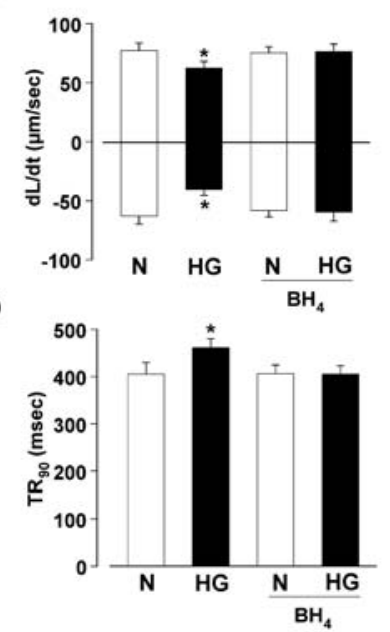

F

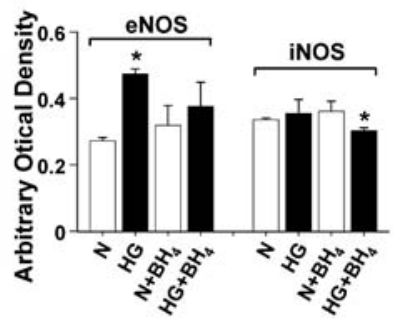

Fig. 4A-F. Effect of the NOS cofactor $\mathrm{BH}_{4}(10 \mu \mathrm{mol} / \mathrm{l})$ on contractile properties and NOS protein expression in myocytes cultured for $24 \mathrm{~h}$ in normal or high glucose medium. A Peak shortening (PS); B maximal velocities of shortening/relengthening $( \pm \mathrm{dL} / \mathrm{dt})$; C time-to-peak shortening (TPS); D time-to$90 \%$ relengthening $\left(\mathrm{TR}_{90}\right)$; E Representative gels depicting immunostaining using anti-eNOS and anti-iNOS antibodies; $\mathbf{F}$ Protein abundance of eNOS and iNOS in normal and high glucose myocytes incubated with or without $\mathrm{BH}_{4}$ from three isolations. Means \pm SEM, $n=58-62$ cells/group for panel A-D and $n=3$ for panel $\mathbf{F}$. ${ }^{*} p<0.05$ vs normal group

Influence of MnTBAP, PTIO and SOD on high glucose-induced intracellular Ca2+ abnormalities. Our previous studies have shown that the high glucose-induced mechanical dysfunction is caused by abnormal intracellular $\mathrm{Ca}^{2+}$ homeostasis [23, 24, 25]. To evaluate the potential mechanism of action involved in high glucose-induced cardiac defects, the influence of MnTBAP, PTIO and L-NMMA on intracellular $\mathrm{Ca}^{2+}$ properties was tested. Resting $\left[\mathrm{Ca}^{2+}\right]_{i}$, electrical stimulus-induced increase in intracellular $\mathrm{Ca}^{2+}\left(\Delta\left[\mathrm{Ca}^{2+}\right]_{\mathrm{i}}\right)$, and cytosolic free $\mathrm{Ca}^{2+}$ decrease rate (tau) were evaluated in fura- 2 loaded myocytes. High glucose myocytes showed similar resting $\left[\mathrm{Ca}^{2+}\right]_{\mathrm{i}}$, reduced $\Delta\left[\mathrm{Ca}^{2+}\right]_{\mathrm{i}}$ associated with slowed cytosolic-free $\mathrm{Ca}^{2+}$ decrease compared to normal myocytes $(p<0.05)$, consistent with reduced peak shortening and prolonged $\mathrm{TR}_{90}$. MnTBAP $(100 \mu \mathrm{mol} / \mathrm{l})$ and L-NMMA $(100 \mu \mathrm{mol} / \mathrm{l})$ abolished the high glucose-induced reduction of $\Delta\left[\mathrm{Ca}^{2+}\right]_{\mathrm{i}}$ and prolonged cytosolic free $\mathrm{Ca}^{2+}$ decrease (Fig. 6). PTIO $(100 \mu \mathrm{mol} / \mathrm{l})$ reduced $\Delta\left[\mathrm{Ca}^{2+}\right]_{\mathrm{i}}$ in nor-

A

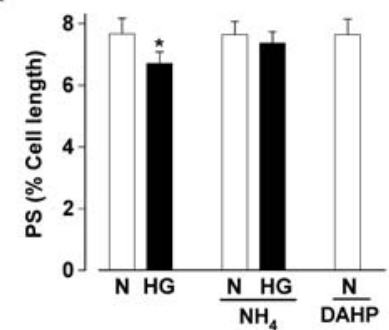

C

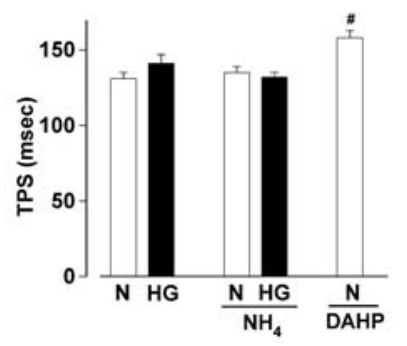

B

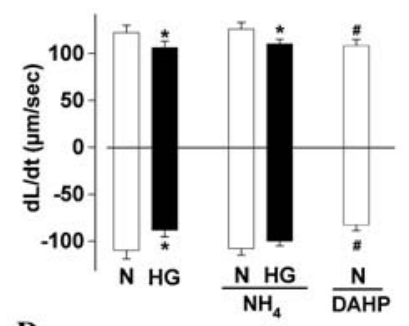

D

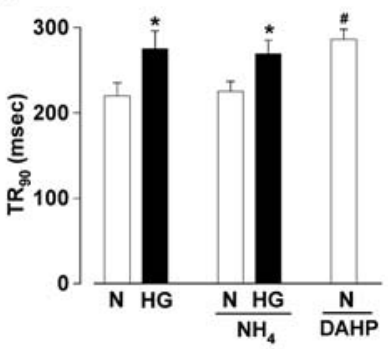

Fig. 5A-D. Effect of the $\mathrm{BH}_{4}$ analogue $\mathrm{NH}_{4}(10 \mu \mathrm{mol} / \mathrm{l})$ on contractile properties in myocytes cultured for $24 \mathrm{~h}$ in normal or high glucose medium. Myocytes were also co-incubated with the GTP cyclohydrolase I inhibitor DAHP (1 mmol/l) for $24 \mathrm{~h}$ in nromal medium to inhibit $\mathrm{BH}_{4}$ synthesis. A Peak shortening (PS); B maximal velocities of shortening/relengthening $( \pm \mathrm{dL} / \mathrm{dt})$; C time-to-peak shortening (TPS); D time-to-90\% relengthening $\left(\mathrm{TR}_{90}\right)$; Mean \pm SEM, $n=48-50$ cells/group. $* p<0.05$ vs normal group, $\# p<0.05$ vs non-drug supplemented normal group

A

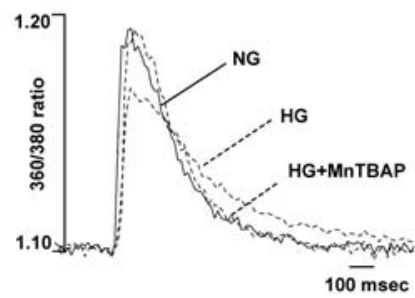

C

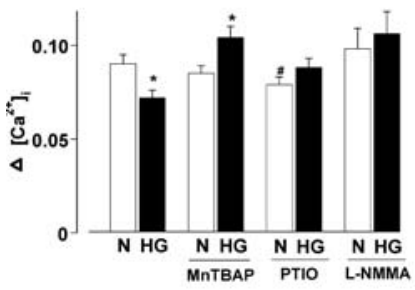

B

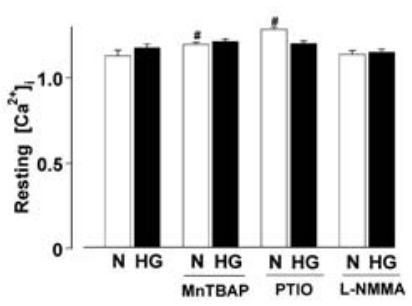

D

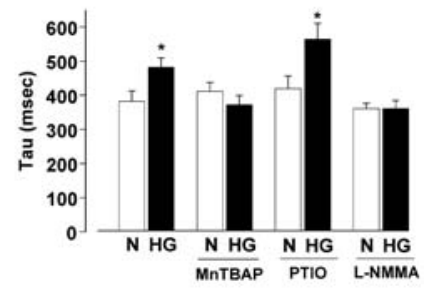

Fig. 6A-D. Intracellular $\mathrm{Ca}^{2+}$ transient properties in fura-2loaded ventricular myocytes cultured for $24 \mathrm{~h}$ in normal or high glucose medium, with or without MnTBAP $(100 \mu \mathrm{mol} / \mathrm{l})$, PTIO $(100 \mu \mathrm{mol} / \mathrm{l})$ or L-NMMA $(100 \mu \mathrm{mol} / \mathrm{l})$. A Representative traces of fura-2 fluorescence ratio in myocytes from normal, high glucose and high glucose+MnTBAP group; B Baseline intracellular $\mathrm{Ca}^{2+}$ concentrations; $\mathbf{C}$ Increase in intracellular $\mathrm{Ca}^{2+}$ transient in response to electrical stimulus; $\mathbf{D}$ rate of cytosolic free $\mathrm{Ca}^{2+}$ decrease (tau). Means \pm SEM. $n=48-55$ cells/group. ${ }^{*} p<0.05$ vs respective normal group, $\# p<0.05$ vs non-drug supplemented normal group 


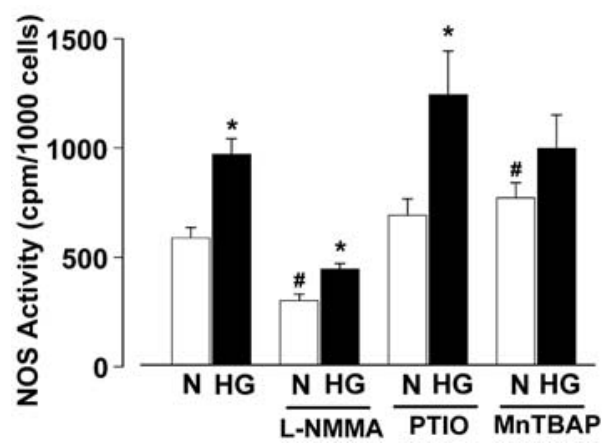

Fig. 7. NOS activity in ventricular myocytes cultured for $24 \mathrm{~h}$ in normal or high glucose medium, with or without L-NMMA $(100 \mu \mathrm{mol} / \mathrm{l})$, PTIO $(100 \mu \mathrm{mol} / \mathrm{l})$ or MnTBAP $(100 \mu \mathrm{mol} / \mathrm{l})$. Means \pm SEM. $n=13$ assays. $* p<0.05$ vs respective normal group, $\# p<0.05$ vs non-drug supplemented normal group

mal myocytes. MnTBAP and PTIO both increased the resting $\left[\mathrm{Ca}^{2+}\right]_{\mathrm{i}}$ in normal myocytes $(p<0.05)$.

Influence of L-NMMA, PTIO and MnTBAP on NOS activity in $N$ and high glucose myocytes. To evaluate the effect of high glucose on NOS activity, NOS activity was measured with ${ }^{3} \mathrm{H}$-arginine to ${ }^{3} \mathrm{H}$-citrulline conversion assay in normal and high glucose myocytes with or without L-NMMA, PTIO, or MnTBAP $(100 \mu \mathrm{mol} / \mathrm{l}$ each). None of these drugs elicited any significant effect on the uptake of ${ }^{3} \mathrm{H}$-arginine into the myocytes as determined by the radioactivity in the ${ }^{3} \mathrm{H}-$ loaded cell pellets after centrifugation. Consistent with the observation from western blot analysis (Fig. 4), high glucose increased NOS activity $(p<0.05)$. L-NMMA $(100 \mu \mathrm{mol} / \mathrm{l})$ inhibited NOS activity in myocytes from both groups $(p<0.05)$, as expected. PTIO did not alter NOS activity in either normal or high glucose group. MnTBAP enhanced NOS activity in normal myocytes $(p<0.05)$ but did not affect NOS activity in high glucose myocytes, therefore nullifying the disparity in NOS activity between normal and high glucose groups (Fig. 7).

\section{Discussion}

Our findings confirmed that glucose toxicity contributes to the development of cardiac E-C coupling dysfunction reminiscent of in vivo diabetic cardiomyopathy. More importantly, the high glucose-induced cardiac mechanical dysfunctions could be alleviated by the NOS inhibitor L-NMMA, the NOS cofactor $\mathrm{BH}_{4}$, the $\mathrm{O}_{2}^{-}$scavenger SOD and the $\mathrm{ONOO}^{-}$scavengers urate and MnTBAP (also a SOD mimetic) although not the nitric oxide scavenger haemoglobin nor the nitric oxide trap PTIO. The high glucose-induced myocyte abnormalities were unable to be reconciled by the $\mathrm{BH}_{4}$ analogue pteridine $\mathrm{NH}_{4}$, an antioxidant but not a cofactor for NOS. The involvement of $\mathrm{BH}_{4}$ in the high glucose-induced cardiomyocyte dysfunction was further substantiated by the fact that blockade of $\mathrm{BH}_{4}$ synthesis with the GTP cyclohydrolase I inhibitor DAHP can directly impair cell mechanics in a manner somewhat reminiscent of those induced by high glucose. Increased eNOS but not iNOS protein abundance was observed in association with enhanced NOS activity in high glucose myocytes. These data suggested that NOS, nitric oxide, $\mathrm{O}_{2}^{-}$, and their reaction product $\mathrm{ONOO}^{-}$could play an important role in the glucose toxicity-induced cardiac contractile dysfunction, and possibly in the pathogenesis of the early-stage of diabetic cardiomyopathy.

Hyperglycaemia is the most important predisposing factor for diabetic cardiomyopathy characterized by reduced contractility and prolonged relaxation $[1,3$, 5]. This is supported by the reduced peak shortening, $\pm \mathrm{dL} / \mathrm{dt}$ and prolonged $\mathrm{TR}_{90}$ in high glucose myocytes observed in our study, which could be underscored by reduced intracellular $\mathrm{Ca}^{2+}$ rise and slowed intracellular $\mathrm{Ca}^{2+}$ clearing (Fig. 6) consistent with earlier reports [23, 24, 27, 28]. Although speculations have been made towards the glucose-induced cardiac dysfunction including activation of protein kinase $C$ [29] and altered lipid messenger such as ceramide [30], the role of NOS/nitric oxide signalling in diabetic heart complications did not receive much support over the past years considering that treatment with the NOS inhibitor N $\omega$-nitro-L-arginine methyl ester (L-NAME) attenuated hyperglycaemia $[31,32]$ and improved ventricular function [33] in diabetes. Nevertheless, the direct effect of diabetes on nitric oxide synthesis is still controversial, with either increased $[17,34,35]$ or decreased [17, 36, 37] nitric oxide synthesis. Enhanced cardiac NOS protein expression and activity were reported under diabetes in conjunction with elevated nitric oxide production [17, 18, 19, 33], consistent with our current observation that high glucose enhanced the expression and activity of NOS, and the reversal of cardiomyocyte dysfunction with the NOS inhibitor L-NMMA. High glucose has been shown to elicit an overt increase in eNOS mRNA in endothelial cells $[17,34]$. No change in cardiac NOS mRNA (eNOS and iNOS) was found at initial stages of diabetes $[18,38]$, indicating that increase in cardiac NOS mRNA could be a consequence rather than cause of metabolic defects due to hyperglycaemia. Our findings showed enhanced eNOS but not iNOS protein expression in high glucose myocytes, suggesting a potential temporal separation in glucose-induced response between the two enzymes. The expression or activity of NOS and nitric oxide synthesis might not accurately reflect the bioavailability of nitric oxide due to the rapid inactivation of nitric oxide by free radicals $[34,35]$.

The mechanism behind the increased expression or activity of NOS in diabetic hearts is still not known. The high glucose-induced up-regulation of eNOS pre- 
vented by the antioxidant lipoic acid and $\mathrm{H}_{2} \mathrm{O}_{2}$ could directly induce eNOS mRNA [18], suggesting the potential role of the redox state in the induction of NOS mRNA. ROS has been speculated to play a key role in the pathogenesis of diabetic cardiomyopathy [15]. Parameters of oxidative stress such as lipid hydroperoxides, thiobarbituric acid substances and isoprostanes have been documented in high amounts in diabetic hearts $[15,39]$. High glucose has been shown to induce generation of ROS, probably through glucose autoxidation, formation of advanced glycation end-products and activation of NADPH-oxidase [18, 40, 41]. The high glucose-induced ROS especially $\mathrm{O}_{2}{ }^{-}$is able to quench nitric oxide at a rate that is three times faster than the ability of SOD to degrade $\mathrm{O}_{2}^{-}$. This could explain the observation that the nitric oxide scavenger haemoglobin and the nitric oxide trap PTIO failed to prevent the high glucose-induced cardiac defect, since nitric oxide is quickly quenched by surrounding $\mathrm{O}_{2}^{-}$ molecules to form $\mathrm{ONOO}^{-}$before getting scavenged or trapped by haemoglobin or PTIO. Our data also showed that L-NMMA depressed contractile amplitude (peak shortening) whereas haemoglobin and PTIO depressed $\pm \mathrm{dL} / \mathrm{dt}$ and prolonged TPS in normal myocytes, indicating that tonic nitric oxide release could be essential for normal cardiac contractile function $[7,8]$. These data, in conjunction with the observation that the NOS inhibitor L-NMMA prevented high glucose-induced cardiac dysfunctions, suggested that nitric oxide release, rather than its removal, is more likely to be involved in the glucose toxicityinduced cardiac mechanical dysfunction. Therefore, regulation of NOS activity could contribute, at least in part, to high glucose-induced mechanical dysfunction. Our rationale of enhanced nitric oxide inactivation by $\mathrm{O}_{2}^{-}$in high glucose myocytes is supported by the ability of urate, MnTBAP and SOD to attenuate or prevent the high glucose-induced cardiac contractile defects and intracellular $\mathrm{Ca}^{2+}$ dysregulation. Both $\mathrm{ONOO}^{-}$and $\mathrm{O}_{2}^{-}$can exert direct cardiac depressive actions [12] and their productions are enhanced in diabetes [42]. Although the direct effects of $\mathrm{ONOO}^{-}$and $\mathrm{O}_{2}{ }^{-}$on cardiac myocyte mechanics are beyond the scope of this study, our results provided evidence of the involvement of $\mathrm{ONOO}^{-}$and $\mathrm{O}_{2}^{-}$in the glucose toxicity-induced cardiac E-C coupling. It is not surprising that PTIO failed to affect NOS activity since it traps nitric oxide instead of acting on NOS enzyme. The enhanced NOS activity in response to MnTBAP is not known but could be related to relieve of the oxidation of $\mathrm{ONOO}^{-}$on NOS. Moreover, our fura-2 fluorescent recording data indicated that regulation of intracellular $\mathrm{Ca}^{2+}$ homeostasis could underscore the mechanical effects of the nitric oxide and $\mathrm{ONOO}^{-}$regulators in the high glucose-induced ventricular dysfunction in cardiac myocytes.

Of interest, the NOS cofactor $\mathrm{BH}_{4}$ restored high glucose-induced mechanical dysfunctions and pre- vented a high glucose-elicited increase in eNOS expression. This is further supported by the observation that depletion of $\mathrm{BH}_{4}$ by the GTP cyclohydrolase I inhibitor DAHP directly impaired cell mechanics somewhat similar to high glucose (such as prolonged TPS/TR ${ }_{90}$ and reduced $\pm \mathrm{dL} / \mathrm{dt}$ ). The fact that DAHP did not exactly duplicate the high glucose-induced myocyte dysfunction (such as in peak shortening and TPS) indicates that mechanism(s) other than NOS cofactor could also participate in the regulation of cardiomyocyte mechanical function. Deficiency of $\mathrm{BH}_{4}$ has been shown in diabetes [21]. This could be related to the fact that $\mathrm{BH}_{4}$ is a major target of oxidation by $\mathrm{ONOO}^{-}$, the amount of which is significantly increased in diabetes [42]. Treatment with $\mathrm{BH}_{4}$ was reported to restore endothelial dysfunction in diabetes [43]. Without sufficient $\mathrm{BH}_{4}$, the electrons flowing from the reductase domain to the oxygenase domain on eNOS can be diverted to $\mathrm{O}_{2}$ molecule rather than $\mathrm{L}$-arginine, resulting in the production of $\mathrm{O}_{2}^{-}$rather than nitric oxide, or "eNOS uncoupling" [22]. Our data suggests that "eNOS uncoupling" could play a role in glucose toxicity-associated cardiac dysfunctions. The observation that the $\mathrm{BH}_{4}$ analogue $\mathrm{NH}_{4}$ failed to modify high glucose-induced cardiac dysfunctions suggests that $\mathrm{BH}_{4}$-induced improvement in cardiac mechanical dysfunction under high glucose toxicity could reflect a specific effect on eNOS enzyme rather than being the consequence of a nonspecific antioxidant action.

Experimental limitations. Diabetes mellitus is a complex metabolic disease and its cardiac complications are likely due to multiple factors in addition to hyperglycaemia (such as dyslipidaemia and insulin resistance). It is not possible to replicate these factors all in the same cell culture model. In addition, the enzymatic myocyte isolation procedure could induce iNOS expression and create an artificial effect on iNOS expression in the ventricular myocytes studied. Thus, caution should be taken when extrapolating the current findings to in vivo diabetes or when applying polymixin $\mathrm{B}$ to absorb endotoxin during cell isolation to minimize any artificial effects on iNOS. Although in vitro models allow us to change one factor at a time and to evaluate the resultant cellular consequences, obvious disadvantages must be considered such as lack of the in vivo settings of haemodynamics from cardiac as well as non-cardiac vasculatures.

In conclusion, our study suggests that NOS, nitric oxide, $\mathrm{O}_{2}^{-}$and $\mathrm{ONOO}^{-}$could play roles in the glucose toxicity-induced cardiac dysfunction simulating diabetic cardiomyopathy. Our data indicates that altered NOS signalling related to $\mathrm{BH}_{4}$ deficiency or dysfunction, formation of $\mathrm{O}_{2}^{-}$or $\mathrm{ONOO}^{-}$and accelerated nitric oxide inactivation could be permissive to high glucose-induced contractile and intracellular $\mathrm{Ca}^{2+}$ dysregulations. 
Acknowledgements. The skillful technical assistance from $\mathrm{J}$. Duan, K.K. Hintz and G.E. McFadden is greatly appreciated. This work was supported by grants from American Diabetes Association (7-0-RA-21) and NIH/NCRR (RR-16474). L.B. Esberg is a Ronald McNair Scholar at the University of North Dakota.

\section{References}

1. Sowers JR, Epstein M (1995) Diabetes mellitus and associated hypertension, vascular disease and nephropathy: an update. Hypertension 26:869-879

2. Galderisi M, Anderson KM, Wilson PWF, Levy D (1991) Echocardiographic evidence for the existence of a distinct diabetic cardiomyopathy (the Framingham Heart Study). Am J Cardiol 68:85-89

3. Ren J, Davidoff AJ (1997) Diabetes rapidly induces contractile dysfunctions in isolated ventricular myocytes. Am J Physiol Heart Circ Physiol 272:H148-H158

4. Hofmann PA, Menon V, Gannaway KF (1995) Effects of diabetes on isometric tension as a function of $\left[\mathrm{Ca}^{2+}\right]$ and $\mathrm{pH}$ in rat skinned cardiac myocytes. Am J Physiol Heart Circ Physiol 269:H1656-H1663

5. Lagadic-Gossmann DL, Buckler KJ, Le Prigent K, Feuvray D (1996) Altered $\mathrm{Ca}^{2+}$ handling in ventricular myocytes isolated from diabetic rats. Am J Physiol Heart Circ Physiol 270:H1529-H1537

6. Schaffer SW, Ballard-Croft C, Boerth S, Allo SN (1997) Mechanisms underlying depressed $\mathrm{Na}^{+} / \mathrm{Ca}^{2+}$ exchanger activity in the diabetic heart. Cardiovasc Res 34:129-136

7. Kojda G, Harrison D (1999) Interactions between NO and reactive oxygen species: pathophysiological importance in atherosclerosis, hypertension, diabetes and heart failure. Cardiovasc Res 43:562-571

8. Ren J, Esberg LB, Combs CK, Ren BH, Chen AF (2001) Adenovirus gene transfer of recombinant endothelial nitric oxide synthase alters contractile function in isolated ventricular myocyte via a phosphatidylinositol 3-kinase-dependent pathway. Circulation 104:II-436 (Abstract)

9. Schultz R, Panas DL, Catena R, Moncada S, Olley PM, Lopaschuk GD (1995) The role of nitric oxide in cardiac depression induced by interleukin- $1 \beta$ and tumor necrosis factor- $\alpha$. Br J Pharmacol 114:27-34

10. Nickola MW, Wold LE, Colligan PB, Wang GJ, Samson WK, Ren J (2000) Leptin attenuates cardiac contraction in adult rat ventricular myocytes: role of nitric oxide. Hypertension 36:501-505

11. Hibbs JB Jr, Taintor RR, Vavrin Z, Granger DL, Drapier J-C, Amber J, Lancaster JR Jr (1990) Synthesis of nitric oxide from a terminal guanidine nitrogen atom of L-arginine: a molecular mechanism regulating cellular proliferation that targets intracellular iron. In: Moncada S, Higgs EA (eds) Nitric oxide from L-arginine: a bioregulatory system. Excerpta Medica, Amsterdam, pp 189-224

12. Schulz R, Dodge KL, Lopaschuk GD, Clanachan AS (1997) Peroxynitrite impairs cardiac contractile function by decreasing cardiac efficiency. Am J Physiol Heart Circ Physiol 272:H1212-H1219

13. Gutierrez HH, Nieves B, Chumley P, Rivera A, Freeman BA (1996) Nitric oxide regulation of superoxide-dependent lung injury: oxidant-protective actions of endogenously produced and exogenously administered nitric oxide. Free Rad Biol Med 21:43-52

14. Goda N, Suematsu M, Mukai M, Kiyokawa K, Natori M, Nozawa S, Ishimura Y (1996) Modulation of mitochondri- on-mediated oxidative stress by nitric oxide in human placental trophoblastic cells. Am. J. Physiol. Heart Circ Physiol 271:H1893-H1899

15. Rösen P, Du X, Tschope D (1998) Role of oxygen derived radicals for vascular dysfunction in the diabetic heart: prevention by alpha-tocopherol? Mol Cell Biochem 188:103111

16. Rösen P, Ballhausen Th, Stockklauser K (1996) Impairment of endothelium dependent relaxation in the diabetic rat heart: mechanisms and implications. Diabetes Res Clin Pract 31:S143-S155

17. Pieper GM (1998) A review of alterations in endothelial nitric oxide production in diabetes: protective role of arginine on endothelial dysfunction. Hypertension 31:1047-1060

18. Stockklauser-Farber K, Ballhausen T, Laufer A, Rosen P (2000) Influence of diabetes on cardiac nitric oxide synthase expression and activity. Biochim Biophys Acta 1535: $10-20$

19. Hintz KK, Wold LE, Colligan PB, Scott GI, Lee KJ, Sowers JR, Ren J (2001) Influence of ovariectomy on ventricular myocyte contraction in simulated diabetes. J Biomed Sci 8:307-313

20. Bagi Z, Koller A (2003) Lack of nitric oxide mediation of flow-dependent arteriolar dilation in type I diabetes is restored by sepiapterin. J Vasc Res 40:47-57

21. Meininger CJ, Marinos RS, Hatakeyama K, MartinezZaguilan R, Rojas JD, Kelly KA, Wu G (2000) Impaired nitric oxide production in coronary endothelial cells of the spontaneously diabetic BB rat is due to tetrahydrobiopterin deficiency. Biochem J 349:353-356

22. Laursen JB, Somers M, Kurz S, McCann L, Warnholtz A, Freeman BA, Tarpey M, Fukai T, Harrison DG (2001) Endothelial regulation of vasomotion in apoE-deficient mice: implications for interactions between peroxynitrite and tetrahydrobiopterin. Circulation 103:1282-1288

23. Ren J, Dominguez LJ, Sowers JR, Davidoff AJ (1996) Troglitazone attenuates high glucose-induced abnormalities in relaxation and intracellular calcium in rat ventricular myocytes. Diabetes 45:1822-1825

24. Ren J, Gintant GA, Miller RE, Davidoff AJ (1997) High extracellular glucose impairs cardiac E-C coupling in a glycosylation-dependent manner. Am J Physiol Heart Circ Physiol 273:H2876-H2883

25. Davidoff AJ, Ren J (1997) Low insulin and high glucose induce abnormal relaxation in cultured adult rat ventricular myocytes. Am J Physiol Heart Circ Physiol 272:H159H167

26. Norby FL, Wold LE, Duan J, Hintz KK, Ren J (2002) IGFI attenuates diabetes-induced cardiac contractile dysfunction in ventricular myocytes. Am J Physiol Endocrinol Metab 283:E658-E666

27. Barbagallo M, Shan J, Pang PK, Resnick LM (1995) Glucose-induced alterations of cytosolic free calcium in cultured rat tail artery vascular smooth muscle cells. J Clin Invest 95:763-767

28. Smogorzewski M, Galfayan V, Massry SG (1998) High glucose concentration causes a rise in $\left[\mathrm{Ca}^{2+}\right]_{\mathrm{i}}$ of cardiac myocytes. Kidney Int 53:1237-1243

29. Yuan SY, Ustinova EE, Wu MH, Tinsley JH, Xu W, Korompai FL, Taulman AC (2000) Protein kinase C activation contributes to microvascular barrier dysfunction in the heart at early stages of diabetes. Circ Res 87:412-417

30. Colligan PB, Relling DP, Ren J (2202) Ceramide reduces high glucose-induced diabetic cardiomyopathy in adult rat ventricular myocytes. Cell Mol Biol 48:OL251-OL257

31. Kolb H, Kiesel U, Kroncke KD, Kolb-Bachofen V (1991) Suppression of low dose streptozotocin induced diabetes in 
mice by administration of a nitric oxide synthase inhibitor. Life Sci 49:PL213-PL217

32. Papaccio G, Esposito V, Latronico MV, Pisanti FA (1995) Administration of a nitric oxide synthase inhibitor does not suppress low-dose streptozotocin-induced diabetes in mice. Int J Pancreatol 17:63-68

33. Smith JM, Paulson DJ, Romano FD (1997) Inhibition of nitric oxide synthase by L-NAME improves ventricular performance in streptozotocin-diabetic rats. J Mol Cell Cardiol 29:2393-2402

34. Cosentino F, Hishikawa K, Katusic ZS, Lüscher TF (1997) High glucose increases nitric oxide synthase expression and superoxide anion generation in human aortic endothelial cells. Circulation 96:25-28

35. Graier WF, Simecek S, Kukovetz WR, Kostner GM (1996) High D-glucose-induced changes in endothelial $\mathrm{Ca} 2+$ / EDRF signaling are due to generation of superoxide anions. Diabetes 45:1386-1395

36. Balon, TW, Nadler JL (1997) Evidence that nitric oxide increases glucose transport in skeletal muscle. J Appl Physiol 82:359-363

37. Trachtman, H, Futterweit S, Crimmins DL (1997) High glucose inhibits nitric oxide production in cultured rat mesangial cells. J Am Soc Nephrol 8:1276-1282

38. Felaco M, Grilli A, De Lutiis MA, Patruno A, Libertini N, Taccardi AA, Di Napoli P, Di Giulio C, Barbacane R, Conti P (2001) Endothelial nitric oxide synthase (eNOS) expres- sion and localization in healthy and diabetic rat hearts. Ann Clin Lab Sci. 31:179-186

39. Pekiner B, Ulusu NN, Das-Evcimen N, Sahilli M, Aktan F, Stefek M, Stolc S, Karasu C; Antioxidants in DiabetesInduced Complications Study Group (2002) In vivo treatment with stobadine prevents lipid peroxidation, protein glycation and calcium overload but does not ameliorate $\mathrm{Ca}^{2+}$-ATPase activity in heart and liver of streptozotocindiabetic rats: comparison with vitamin E. Biochim Biophys Acta 1588:71-78

40. Yan SD, Schmidt AM, Anderson GM, Zhang J, Brett J, Zhou YS, Pinsky D, Stern D (1994) Enhanced cellular oxidant stress by the interaction of advanced glycation end products with their receptors/binding proteins. J Biol Chem 269:9889-9897

41. Giardino I, Edelstein D, Brownlee M (1996) BCL-2 expression or antioxidants prevent hyperglycaemia-induced formation of intracellular advanced glycation end-products in bovine endothelial cells. J Clin Invest 94:110-117

42. Tannous M, Rabini RA, Vignini A, Moretti N, Fumelli P, Zielinski B, Mazzanti L, Mutus B (1999) Evidence for iNOS-dependent peroxynitrite production in diabetic platelets. Diabetologia 42:539-544

43. Pieper GM (1997) Acute amelioration of diabetic endothelial dysfunction with a derivative of the nitric oxide synthase cofactor, tetrahydrobiopterin. J Cardiovasc Pharmacol 29:8-15 